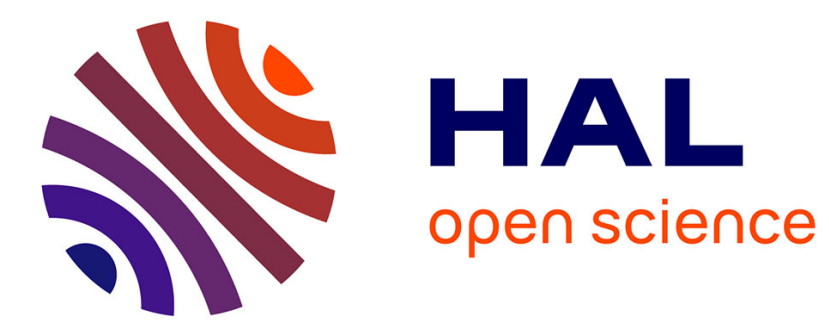

\title{
On the Homogeneity of Single Phase Obtained in Metallic Systems with Positive Heat of Mixing
}

\author{
J. Mimault, O. Proux, R. Elkalkouli, T. Girardeau
}

\section{To cite this version:}

J. Mimault, O. Proux, R. Elkalkouli, T. Girardeau. On the Homogeneity of Single Phase Obtained in Metallic Systems with Positive Heat of Mixing. Journal de Physique IV Proceedings, 1997, 7 (C2), pp.C2-1025-C2-1026. 10.1051/jp4:19972127 . jpa-00255186

\section{HAL Id: jpa-00255186 https://hal.science/jpa-00255186}

Submitted on 1 Jan 1997

HAL is a multi-disciplinary open access archive for the deposit and dissemination of scientific research documents, whether they are published or not. The documents may come from teaching and research institutions in France or abroad, or from public or private research centers.
L'archive ouverte pluridisciplinaire HAL, est destinée au dépôt et à la diffusion de documents scientifiques de niveau recherche, publiés ou non, émanant des établissements d'enseignement et de recherche français ou étrangers, des laboratoires publics ou privés. 


\title{
On the Homogeneity of Single Phase Obtained in Metallic Systems with Positive Heat of Mixing
}

\author{
J. Mimault, O. Proux, R. Elkalkouli and T. Girardeau
}

\author{
Laboratoire de Métallurgie Physique, URA 131 du CNRS, Université de Poitiers, U.F.R. Sciences \\ Fondamentales et Appliquées, SP2MI, Boulevard 3, Téléport 2, BP. 179, 86960 Futuroscope cedex, \\ France
}

\begin{abstract}
X-ray diffraction and absorption spectroscopy measurements have been performed in metastable solid materials obtained by mechanical attrition or codeposition process of immiscible systems in view to investigate the short and long range order obtained inside these solutions. Firstly, experiments show that $\mathrm{Cu}_{80} \mathrm{Fe}_{10} \mathrm{Co}_{10}$ milled powders are in quasi perfect solid solution; this result arouses interest because giant magnetoresistance is more readily controlled by decomposition of a supersatured solid solution. Secondly, codeposition of $\mathrm{Cu}_{50} \mathrm{Mo}_{50}$ presents a long range order typical of a well-defined cristalline structure whereas the short range order appears very disordered.
\end{abstract}

\section{Introduction}

The present paper describes the structure (long and local range order) of some original materials generated from binary or ternary systems, chosen for their positive heat of mixing. Here, we focus attention on two examples where the microstructures were obtained by using two very different alloying techniques which have received a large development during the last decades : a mechanical alloying process applied to a mixed $\mathrm{Cu} / \mathrm{Fe} / \mathrm{Co}$ powder and attempted to synthesize a granular material, physically characterized by a giant magnetoresistance effect and a physical vapor deposition process used on a $\mathrm{Cu} / \mathrm{Mo}$ mixed target with the aim to obtain a protective coating which improves the tribological performances.

\section{Experimental}

Using $\mathrm{Cu} \mathrm{K} \alpha$ radiation, long range order is revealed by X-ray diffraction patterns, obtained either by means of a Siemens $\theta-2 \theta$ powder diffractometer in the case of the mechanically alloyed samples or with an home-made set-up X ray diffractometer used in a dispersed mode and asymetric geometry [1] for thin deposited films; a fixed and grazing incidence $\alpha=2^{\circ}$ improves the diffusion efficiency inside coatings. Short range order is evaluated by plotting the X-ray absorption spectra obtained around (from $200 \mathrm{eV}$ under the threshold to $800 \mathrm{eV}$ above) the different absorption K-edges which characterize each studied sample. These experiments were performed at LURE using synchrotron radiation from the DCI storage ring operating with an energy of $1.85 \mathrm{GeV}$. Measurements were carried out in a conversion electron mode on a system working at liquid nitrogen temperature [2]. Samples were orientated in such a way that the electric field was parallel to their surface.

\section{Ball-milling in $\mathrm{Cu} / \mathrm{Fe} / \mathrm{Co}$ system}

In recent years, the giant magnetoresistance effect has been extensively studied in $\mathrm{Co} / \mathrm{Cu}$ and $\mathrm{Fe} / \mathrm{Cu}$ magnetically coupled multilayers. More recently, a growing attention has been paid to granular materials usually obtained by codepositing two immiscible metallic components on a substrate. With $\mathrm{Co} / \mathrm{Cu}$ and $\mathrm{Fe} / \mathrm{Cu}$ systems [3] [4], the two metallic components tend to segregate, resulting in the formation of small magnetic precipitates embedded in a non magnetic matrix. The giant magnetoresistance effect can be emphasized or eroded, according to the temperature and time of a subsequent annealing.

The ball-milling process of multicomponent powders can be an alternative to obtain a similar effect in bulk compacted materials. A series of $\mathrm{Cu}_{80} \mathrm{Co}_{20}, \mathrm{Cu}_{80} \mathrm{Fe}_{20}$ [5] and $\mathrm{Cu}_{80} \mathrm{Fe}_{10} \mathrm{Co}_{10}$ samples has been prepared by milling, at room temperature, a weighted and mixed powder in a Spex 8000 shaker mill. The total mass of powder was about $5 \mathrm{~g}$ and the ratio of the ball to powder was 5 to 1 in weight. Balls and vial were both made of stainless steel and, after a milling time of 65 hours, samples were taken as metallic compacted plaques sticking to the inner walls. Then, they were thinned and polished.

Here, we report only the microstructural investigation obtained on the ternary sample, where annealing induces FeCo body-centered cubic precipitates. Figure 1 shows the $\theta-2 \theta$ X-ray diffraction spectra obtained with this sample, compared to the mixed powder one. One can see that, after milling, all the diffraction peaks which indicate the presence of body-centered cubic iron or hexagonal cobalt have disappeared from the spectrum. On figure 2 the Fourier transforms of the Exafs spectra collected on $\mathrm{Fe}, \mathrm{Co}$ and $\mathrm{Cu}$ absorption $\mathrm{K}$-edge show three quasi identical signals. Nevertheless, a more precise analysis of the backtransformed Exafs signal of the first main peak shows some differences, especially for the Debye-Waller term : assuming that the environment of each atom species is quasi exclusively constituted by $\mathrm{Cu}$ atoms, very good fits are obtained, for the three signals. when first neighbours are located at a distance of $0.2535 \mathrm{~nm}$ from the central excited atom. A mixed environment, in accordance with a perfect sursatured solid solution, only slightly increases this parameter. Simulation also indicates that the 
three spectra are well fitted when the coordination number is taken equal to 12 , the differences being mainly provided by the Debye-Waller term which shows a relative topological disorder around a Fe atom $(\sigma=0.0085 \mathrm{~nm})$ in comparison with the Co one $(\sigma=0.0077 \mathrm{~nm})$ and the $\mathrm{Cu}$ one $(\sigma=0.0069 \mathrm{~nm})$, this former being typical of copper bulk at $80 \mathrm{~K}$.

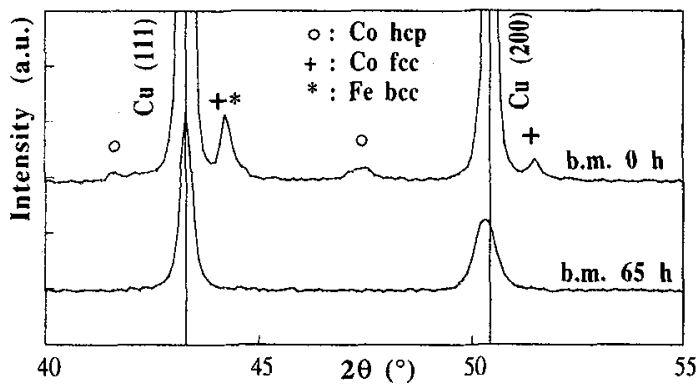

Fig. 1: X-ray diffraction patterns of the $\mathrm{Cu}_{80} \mathrm{Fe}_{10} \mathrm{Co}_{10}$ samples before (b.m. 0 h) and after (b.m. 65 h) ball-milling.

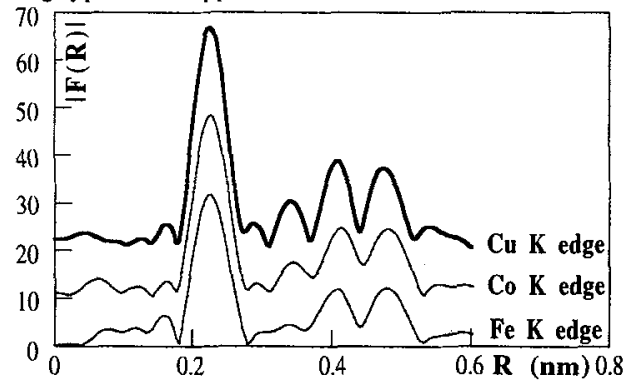

Fig. 2: Fourier Transform ot the EXAFS signal of the $\mathrm{Cu}_{80} \mathrm{Fe}_{10} \mathrm{Co}_{10}$ sampie b.m. $65 \mathrm{~h}$ at the 3 different $\mathrm{K}$ edges.

\section{Co-deposited Cu $\mathrm{M}_{\mathbf{X}} \mathrm{O}_{\mathrm{x}}$ thin films}

Tribological properties of thin film coatings on a metal substrate are greatly influenced by their microstructures and composition. In particular, thin nanocristalline films of copper and molybdenium co-deposited on steel substrates were found [6] to improve, sometimes drastically, the wear coefficient when composition is included within the domain $0.7>x>0.5$. The c)-deposition is produced by ion beam sputtering technique and a split-target arrangement. A precise measurement of composition was achieved by energy $x$-ray dispersive spectrometry. Sample thickness was chosen about $300 \mathrm{~nm}$, because of the limited probing depth in conversion electron X-ray spectroscopy mode. Here, we report only results about the long and short range order encountered in the $\mathrm{Cu}_{50} \mathrm{Mo}_{50}$. Among the whole series of probed specimens, this composition presents the most typical short range deviations from a random distribution of atoms in a solid solution identified on the X-ray diffraction pattern reported on figure 3. This set of peaks is typical of a body cubic centered cristalline phase, which the dense plane family (110) displays a lattice spacing $d_{11}$ in quasi complete accordance with the Vegard's law ; apart the (200) peak, partially truncated by the diffractometer geometry, positions of the (211) and (220) peaks are in coherence (see arrows) with this distance. Compared with that simple description of the matrix, the EXAFS results appears more complex; the Fourier transforms (figure 4a and 4b) show environments typical of amorphous materials.

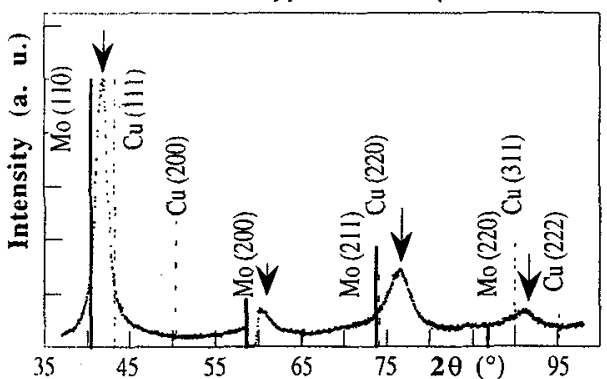

Fig. $3: \mathrm{X}$-ray diffraction pattern of the $\mathrm{Cu}_{50} \mathrm{Mo}_{50}$ sample in asymetric geometry (incidence : $2^{\circ}$ )

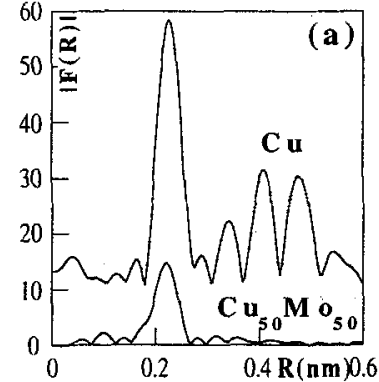

Fig. 4 (a) : Fourier Transforms at the $\mathrm{Cu} \mathrm{K}$ edge

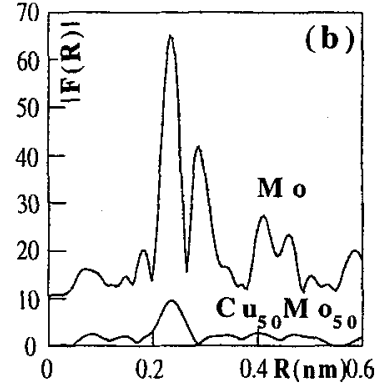

Fig. 4 (b) : Fourier Transforms at the Mo K edge

Analysis of the backtransformed EXAFS signals can be resumed as follow : a) about the first coordination shell ( 8 atoms in BCC structure), the chemical distribution remains coherent with a random sursatered solid solution; but fits require several distances in this first shell : $\mathrm{d}_{\mathrm{Cu}-\mathrm{Cu}} \approx 0.248 \mathrm{~nm}, \mathrm{~d}_{\mathrm{Cu}-\mathrm{Mo}_{\mathrm{O}}} \approx 0.267 \mathrm{~nm}$ and $\mathrm{d}_{\mathrm{Mo}-\mathrm{Mo}} \approx 0.271 \mathrm{~nm}$ with an important disorder for the mixed pairs. b) the second shell appears so disordered that only some (3) Mo-Mo pairs $\left(d_{\text {Mo-Mo }} \approx 0.312 \mathrm{~nm}\right)$ can be extracted. The mean first shell distance value is nevertheless equal to the one deduced from XRD experiment.

\section{References}

[1] A. Naudon, T. Slimani and Ph. Goudeau, Journal of Applied Crystallography 24 (1991) 501-508

[2] J. Mimault. J.J. Faix, T. Girardeau, M. Jaouen and G. Tourillon. Measurement Science and Technology 5 (1994) 482-489

(3) A.E. Berkowitz. J.R. Mitchell, M.J. Carey, A.P. Young, S. Zhang, F.E. Spada, Physical Review Letters 68, 25 (1992) $3745-3748$

[4] M. Sakurai, S.A. Makhlouf, T. Hihara, K. Sumiyama, K. Wakoh and K. Suzuki, Physica B 208-209 (1995) 614-616

[5] R. Elkalkouli, P. Chartier and J.-F. Dinhut, Materials Science Forum 179-181 (1995) 267-272

[6] J. Mimault, K. Reklaoui et T. Girardeau, Revue de Métallurgie, 1.28 (septembre 1994) 1264 